\title{
Article \\ Robust Copper Metal-Organic Framework-Embedded Polysiloxanes for Biomedical Applications: Its Antibacterial Effects on MRSA and In Vitro Cytotoxicity
}

\author{
Kihak Gwon ${ }^{1}{ }^{\oplus}$, Youngmee Kim ${ }^{2}{ }^{\oplus}$, Hyunjun $\mathrm{Cho}^{3}$, Seonhwa Lee ${ }^{1}$, So-Hyeon Yang ${ }^{2}$, Sung-Jin Kim ${ }^{2}$ \\ and Do Nam Lee ${ }^{1, *}$ \\ 1 Ingenium College of Liberal Arts (Chemistry), Kwangwoon University, Seoul 01897, Korea; \\ khgwon@kw.ac.kr (K.G.); seonhwalee@kw.ac.kr (S.L.) \\ 2 Department of Chemistry and Nano Science, Institute of Nano-Bio Technology, Ewha Womans University, \\ Seoul 03760, Korea; ymeekim@ewha.ac.kr (Y.K.); auung22@ewhain.net (S.-H.Y.); sjkim@ewha.ac.kr (S.-J.K.) \\ 3 Department of Chemistry, Dongguk University, Seoul 04620, Korea; vchol1212@dgu.ac.kr \\ * Correspondence: donamlee2@kw.ac.kr; Tel.: +82-2-940-5658
}

check for updates

Citation: Gwon, K.; Kim, Y.; Cho, H.; Lee, S.; Yang, S.-H.; Kim, S.-J.; Lee, D.N. Robust Copper Metal-Organic Framework-Embedded Polysiloxanes for Biomedical Applications: Its Antibacterial Effects on MRSA and In Vitro Cytotoxicity. Nanomaterials 2021, 11, 719. https://doi.org/10.3390/ nano11030719

Academic Editor: Fernando Novio

Received: 14 February 2021

Accepted: 8 March 2021

Published: 12 March 2021

Publisher's Note: MDPI stays neutral with regard to jurisdictional claims in published maps and institutional affiliations.

Copyright: (c) 2021 by the authors. Licensee MDPI, Basel, Switzerland. This article is an open access article distributed under the terms and conditions of the Creative Commons Attribution (CC BY) license (https:/ / creativecommons.org/licenses/by/ $4.0 /)$.

\begin{abstract}
Polysiloxanes (PSs) have been widely utilized in the industry as lubricants, varnishes, paints, release agents, adhesives, and insulators. In addition, their applications have been expanded to include the development of new biomedical materials. To modify PS for application in therapeutic purposes, a flexible antibacterial Cu-MOF (metal-organic framework) consisting of glutarate and 1,2bis(4-pyridyl)ethane ligands was embedded in PS via a hydrosilylation reaction of vinyl-terminated and H-terminated PSs at $25^{\circ} \mathrm{C}$. The bactericidal activities of the resulting Cu-MOF-embedded PS (PS@Cu-MOF) and the control polymer (PS) were tested against Escherichia coli, Staphylococcus aureus, and methicillin-resistant Staphylococcus aureus. PS@Cu-MOF exhibited more than 80\% bactericidal activity toward the tested bacteria at a concentration of $100 \mu \mathrm{g} \cdot \mathrm{mL}^{-1}$ and exhibited a negligible cytotoxicity toward mouse embryonic fibroblasts at the same concentration. Release tests of the $\mathrm{Cu}$ (II) ion showed PS@Cu-MOF to be particularly stable in a phosphate-buffered saline solution. Furthermore, its physical and thermal properties, including the phase transition, rheological measurements, swelling ratio, and thermogravimetric profile loss, were similar to those of the control polymer. Moreover, the low cytotoxicity and bactericidal activities of PS@Cu-MOF render it a promising candidate for use in medicinal applications, such as in implants, skin-disease treatment, wound healing, and drug delivery.
\end{abstract}

Keywords: Cu-MOF; polysiloxane (PS); hydrosilylation; antibacterial agent; cytocompatibility; biomedical application

\section{Introduction}

The use of antimicrobial plastics has attracted considerable attention in medicinal and biomedical engineering fields in recent years. Medical polymers must be harmless to the living body, wherein they should exhibit a high biocompatibility with tissues, cells, and blood to avoid immune rejection reactions, and they must maintain their necessary physical and mechanical properties within the host [1-9]. Polysiloxane (PS) materials exhibit interesting properties including good thermal and oxidative stabilities, dielectric insulating properties, fouling release properties, and excellent biocompatibilities [10,11]. As a result, PSs have been widely utilized in the industry as lubricants, varnishes, paints, release agents, adhesives, and insulators [12-18]. In addition, due to their physicochemical properties, the uses of PS have been expanded to include medical materials such as tubes, pre-coating needles, syringes, artificial heart valves, pacemakers, and contact lenses [19-21]. Many studies have therefore been conducted to develop a surface modification method to impart antibacterial properties to PS for its use in biological applications. In fact, many 
literature reports have indicated that surface-modified PSs exhibit a good antibacterial effect when coated with silver nanoparticles, organic antibiotics, quaternary ammonium salts, chitosan, and antimicrobial drugs or other materials [22-33].

Recently, metal-organic frameworks (MOFs), which are porous coordination materials composed of organic ligands and metal ions, have received considerable interest as antibacterial materials for biological, environmental, and food applications, owing to their sustained release capability, porosity, structural flexibility, and antibacterial properties [34-38]. However, the release of excess metal ions from MOFs can have toxic effects on the host tissues, as well as microbes, and so it is desirable to improve their stabilities [39-41]. Considerable efforts have therefore been expended to improve the antibacterial durabilities of such materials and to reduce any adverse effects. This has been achieved by covalently introducing biocidal functions to the polymer [42,43]. Recently, our group developed a series of stable antibacterial MOFs (i.e., $\mathrm{Cu}$-, $\mathrm{Co}$-, and $\mathrm{Zn}$-based MOFs), which were embedded into photo cross-linkable hydrogels for drug delivery. Importantly, the Cu-MOFembedded hydrogels exhibited an excellent bactericidal activity against both Escherichia coli and Staphylococcus aureus, with no observed cytotoxicity [44]. Notably, we reported that $\mathrm{Cu}-\mathrm{MOF}$ containing glutarate (Glu) and bis(4-pyridyl) ligands showed very excellent bioactivity toward various bacteria [45].

Thus, we herein report the development of a simple antibacterial Cu-MOF-embedded PS scaffold with negligible toxicity, which is prepared via a hydrosilylation method. More specifically, an antibacterial Cu-MOF containing Glu and 1,2-bis(4-pyridyl)ethane (bpa) is prepared, using a previously reported method, and embedded on PS via hydrosilylation reactions with vinyl-terminated PS (PS-vinyl) and hydrogen-terminated PS (PS-H) at $25^{\circ} \mathrm{C}$. Their characterizations were investigated using powder X-ray diffraction (PXRD), differential scanning calorimetry (DSC), thermogravimetric analysis (TGA), Fourier-transform infrared spectroscopy (FT-IR), rheological measurements, scanning electron microscopyenergy dispersive $\mathrm{X}$-ray spectroscopy (SEM-EDS), and inductively coupled plasma mass spectrometry (ICP-MS). Overall, this study focuses on the development of a new type of antibacterial PS, which can be widely applied in drug delivery, wound healing, and antibacterial coatings for medical devices and implants, as determined by the evaluation of the antibacterial activity against Escherichia coli (E. coli), Staphylococcus aureus (S. aureus), and methicillin-resistant Staphylococcus aureus (MRSA). The in vitro cytotoxicity of PS and PS@Cu-MOF against mouse embryonic fibroblasts is also examined and discussed.

\section{Materials and Methods}

\subsection{Preparation of the $\mathrm{Cu}-\mathrm{MOF}$}

The Cu-MOF, consisting of glutarate (Glu) and bpa ligands, was synthesized hydrothermally via a previously reported method, and its formula was determined to be $\left(\mathrm{Cu}_{2}(\mathrm{Glu})_{2}(\mathrm{bpa})\right) \cdot 3 \mathrm{H}_{2} \mathrm{O}[45,46]$. More specifically, a mixture of $\mathrm{Cu}\left(\mathrm{NO}_{3}\right)_{2} \cdot 3 \mathrm{H}_{2} \mathrm{O}(2.0 \mathrm{mmol}$, 99\%, Sigma-Aldrich, St. Louis, MO, USA), glutaric acid (2.0 mmol, 99\%, Sigma-Aldrich, St. Louis, MO, USA), and bpa (1.0 mmol, 99\%, Sigma-Aldrich, St. Louis, MO, USA) was prepared in distilled water containing $1.0 \mathrm{M} \mathrm{NaOH}$, and the hydrothermal reaction was carried out at $80^{\circ} \mathrm{C}$ as reported. The obtained Cu-MOF was analyzed by PXRD and FT-IR.

\subsection{Preparation of PS and the Cu-MOF-Embedded PS (PS@Cu-MOF)}

The Cu-MOF-embedded PS (PS@Cu-MOF) was prepared through a hydrosilylation reaction between two PS components with a $\mathrm{TiO}_{2}$ additive in the presence of a Pt catalyst (KE-1300 and CAT-1300, Shin-Etsu Chem. Co., Tokyo, Japan) and Cu-MOF. More specifically, the vinyl-terminated PS (PS-vinyl) containing the Pt catalyst and $\mathrm{TiO}_{2}$ additive was mixed thoroughly with the Cu-MOF $\left(100 \mu \mathrm{g} \cdot \mathrm{mL}^{-1}\right)$ for $10 \mathrm{~min}$, and then the hydrogenterminated PS (PS-H) was added to the mixture (10:1 weight ratio of vinyl/hydrogen) and thoroughly mixed for an additional $5 \mathrm{~min}$. Subsequently, the mixture was degassed under vacuum and pipetted into a $50 \times 50 \mathrm{~mm}^{2}$ glass mold prior to vulcanizing for $24 \mathrm{~h}$ at $25^{\circ} \mathrm{C}$. PS alone (i.e., without the $\mathrm{Cu}-\mathrm{MOF}$ ) was also prepared in the same manner and employed 
as a positive control. The obtained polymers were characterized by PXRD, DSC, TGA, SEM-EDS, Rheometer, and ICP-MS.

\subsection{Instrumentation}

PXRD patterns of Cu-MOF, PS, and PS@Cu-MOF were recorded using a Rigaku MiniFlex diffractometer (Rigaku Corp, Neu-Isenburg, Germany). The FT-IR spectrum was measured on a Bio-Rad FTS 135 spectrometer (Hercules, CA, USA). DSC runs were carried out using a DSC 214 Polyma (NETZSCH, Burlington, MA, USA). TGA was performed using a TG 209 F3 Tarsus ${ }^{\circledR}$ instrument (NETZSCH, Burlington, MA, USA). The surface morphology and elemental composition of PS and the PS@Cu-MOF scaffolds were characterized using SEM-EDS (FE-SEM, JEOL JSM-5800F, Peabody, MA, USA). The mechanical properties of PS and PS@Cu-MOF were evaluated using a TA rheometer (Discovery HR 10, New Castle, DE, USA). The degradation of PS@Cu-MOF was carried out by ICP-MS (Agilent Marker 7700, RF Generator Power 1550 W, Tokyo, Japan). The colorimetric absorbance was determined using a microplate reader (Synergy H1, BioTek, Winooski, VT, USA), and the live/dead double-stained cells were imaged by fluorescence microscopy (IX83, Olympus, Center Valley, PA, USA).

\subsection{Mechanical Properties of the PS@Cu-MOF}

For the rheological measurements, PS@Cu-MOF and PS $(8 \mathrm{~mm}$ in diameter, $1 \mathrm{~mm}$ thickness) were prepared and soaked in $0.01 \mathrm{M} \mathrm{pH} 7.4 \mathrm{PBS}$ for $2 \mathrm{~d}$ at $37^{\circ} \mathrm{C}$. The frequency sweep test (from 0.01 to $100 \mathrm{rad} / \mathrm{s}$ ) was tested at $1 \%$ strain and $25^{\circ} \mathrm{C}$. To quantify the swelling ratios of PS and PS@Cu-MOF, both samples were allowed to reach their fully swollen states and then weighed (Ws) after drying the outer surface carefully with a tissue. Each sample was then lyophilized for two days and weighed (Wd), and the swelling ratios were calculated as follows:

$$
\text { Swelling ratio }=\frac{\mathrm{Ws}}{\mathrm{Wd}}
$$

\subsection{Degradation and Metal Ion Release Tests}

To assess whether PS@Cu-MOF could release its constituent metal ions, each of the four solutions containing PS@Cu-MOF was prepared at concentration of $1 \mathrm{mg} \cdot \mathrm{mL}^{-1}$ in $0.9 \%$ phosphate-buffered saline (PBS) and stirred at $25^{\circ} \mathrm{C}$ for $6,12,24$, or $48 \mathrm{~h}$. Subsequently, each sample was subjected to centrifugation, and the supernatant was separated from the reaction tube. The quantity of $\mathrm{Cu}$ (II) ions released was measured by ICP-MS analysis of the supernatant. The degree of degradation was expressed as the concentration of $\mathrm{Cu}$ (II) ions released into the PBS, in $\mu \mathrm{g} \cdot \mathrm{mL}^{-1}$, at each release test time.

\subsection{Antibacterial Tests}

Antibacterial activity tests on PS and PS@Cu-MOF were carried out using the following three strains of bacteria: E. coli (ATCC 8739), S. aureus (ATCC 6538P), and MRSA (ATCC 33591), according to a previously reported colony counting method [44]. More specifically, to measure the antibacterial activity of PS@Cu-MOF against the three bacterial strains, three specimens of PS@Cu-MOF and a stomacher film for the blank $(5 \times 5 \pm 0.2 \mathrm{~cm}$, within $1 \mathrm{~cm}$ thickness) were prepared and tested according to the following method. As a positive control, PS (without the MOF) was also prepared and evaluated. The sample was completely dried after wiping three times with an ethanol-soaked gauze. The pre-cultured test bacteria with a concentration of $\sim 10^{5} \mathrm{cfu} \cdot \mathrm{mL}^{-1}$ (colony-forming units) were routinely inoculated. Each test sample was placed in a Petri dish with the test side up. Subsequently, an aliquot $(200 \mu \mathrm{L})$ of the test solution was inoculated onto each test piece. The film placed on the dropped test bacterium was lightly pressed to cover it with the test bacterium. The test sample, and the control inoculated with the test strain, were incubated for $24 \mathrm{~h}$ at $37^{\circ} \mathrm{C}$. After inoculation, the uncoated test pieces bearing the test strain were immediately separated using sterilized tweezers, and SCDLP medium $(10 \mathrm{~mL})$ was added to wash off the test bacteria. The viable cell count of this washing solution was measured. Subsequently, 
$1 \mathrm{~mL}$ of the washing solution was added to the test tube containing $9 \mathrm{~mL}$ of physiological saline solution and mixed well. The washing solution was then diluted stepwise, and an aliquot $(100 \mu \mathrm{L})$ of the diluted solution was placed onto nutrient agar plates and incubated for $24 \mathrm{~h}$ at $37^{\circ} \mathrm{C}$. All experiments were performed in triplicate.

\subsection{Cytotoxicity Assays}

The cytotoxicity of the prepared PS@Cu-MOF was then evaluated as described previously $[44,47]$. More specifically, a fibroblast monolayer was formed on a collagen type I coated glass slide at a density of $3 \times 10^{4}$ cells $\cdot \mathrm{cm}^{-1}$ and incubated for $3 \mathrm{~h}$. Non-adhered cells were then rinsed with Dulbecco's Modified Eagle Medium (DMEM supplemented with $10 \% \mathrm{FBS}, 200 \mathrm{IU} \cdot \mathrm{mL}^{-1}$ penicillin, and $200 \mu \mathrm{g} \cdot \mathrm{mL}^{-1}$ streptomycin), transferred to a 12-well plate, and cultured in the cell culture medium at $37^{\circ} \mathrm{C}$ in a humidified incubator containing 5\% $\mathrm{CO}_{2}$. The following day, the prepared PS@Cu-MOF $\left(100 \mu \mathrm{g} \cdot \mathrm{mL}^{-1}\right.$ $\mathrm{Cu}-\mathrm{MOF}-\mathrm{embedded} \mathrm{PS}, 1.5 \mathrm{~cm}$ diameter) was carefully placed on the cell monolayer and incubated for either 1 or $3 \mathrm{~d}$. Thereafter, the cells were stained using a live/dead doublestaining protocol [48]. The stained cells were imaged by fluorescence microscopy, and the cell viability was quantified by calculating the percentage of live cells among the total cells. In addition, the cytotoxicity of the extract of PS@Cu-MOF was also evaluated by measuring the cell viability in the presence of the extract solution [49]. For this purpose, PS@Cu-MOF was incubated with the cell culture medium $\left(3 \mathrm{~cm}^{2} \mathrm{~mL}^{-1}\right)$ for $24 \mathrm{~h}$ to obtain the extract solution, and the cells were seeded in a 24-well plate at a density of $5 \times 10^{4}$ cells per well. After incubating at $37^{\circ} \mathrm{C}$ for $24 \mathrm{~h}$, the culture medium was replaced in each well using the DMEM medium containing the extract solution $(200 \mu \mathrm{L})$. After incubating for $24 \mathrm{~h}$, the DMEM-containing extract solution was replaced with a fresh medium $(200 \mu \mathrm{L})$. Subsequently, an aliquot $(20 \mu \mathrm{L})$ of the MTS cell proliferation assay kit (Abcam, Cambridge, MA, USA) was added to each well, and incubation was carried out for an additional $4 \mathrm{~h}$. Finally, the colorimetric absorbance of the produced formazan was measured at $490 \mathrm{~nm}$ using a microplate reader. The cell viability was calculated using the following equation:

$$
\text { cell viability }(\%)=\left(\frac{O_{\text {sample }}-O_{\text {blank }}}{O_{\text {control }}-\mathrm{OD}_{\text {blank }}}\right) \times 100
$$

where $\mathrm{OD}_{\text {sample }}$ represents the absorbance of the wells containing the extract solution, $\mathrm{OD}_{\text {control }}$ represents the absorbance of the wells containing only the culture medium, and $\mathrm{OD}_{\text {blank }}$ represents the absorbance of the wells that contained no cells. The cytotoxicity of PS was also determined using the above method.

\section{Results and Discussion}

\subsection{Preparation of the Cu-MOF-Embedded PS (PS@Cu-MOF)}

As described in Figure 1a, the Cu-MOF was synthesized by a hydrothermal reaction between $\mathrm{Glu}$, bpa, and $\mathrm{CuNO}_{3} \cdot 3 \mathrm{H}_{2} \mathrm{O}$ [45]. Its bulk structure was confirmed by PXRD measurements and FT-IR spectroscopy. As illustrated in Figure S1, the main crystalline peaks of $\mathrm{Cu}-\mathrm{MOF}$ appeared at $2 \theta=6.8,13.5$, and $14.9^{\circ}$, which corresponded to the (200), (400), and (420) crystal planes, respectively, and are consistent with previous reported literature [46]. The $\mathrm{Cu}-\mathrm{MOF}$ sample also showed peaks attributed to $\mathrm{C}-\mathrm{H}$ stretching in the region between 650 and $900 \mathrm{~cm}^{-1}$, while the peaks at 1602 and $1412 \mathrm{~cm}^{-1}$ were attributed to bidentate inter cluster bridges and to the stretching bands of $v(C-O)$, respectively (Figure S2) [48]. It was also determined that the crystal structure of $\mathrm{Cu}-\mathrm{MOF}$ contained dinuclear $\mathrm{Cu}_{2}$ units bridged by Glu ligands that formed 2D sheets connected by bpa ligands to give a 3D framework (Figure S3). We prepared PS@Cu-MOF via the facile hydrosilylation reaction of PS-vinyl and $\mathrm{Cu}-\mathrm{MOF}$ with PS-H in the presence of a Pt catalyst and $\mathrm{TiO}_{2}$ additive for $24 \mathrm{~h}$ at $25^{\circ} \mathrm{C}$ (Figure $1 \mathrm{~b}$ ). The proposed curing mechanism of PDMS was initiated by the insertion reaction of PS-H to the Pt catalyst, followed by PS-vinyl to the Pt-complex via a releasing ligand, elimination of PS by a Si-C coupling reaction, and re-coordination of the released ligand to the Pt catalyst as the final step (Figure 1c). Control 
PS was prepared by the same manner without the incorporation of $\mathrm{Cu}-\mathrm{MOF}[50,51]$. As shown in Figure 1d, both PS and the PS@Cu-MOF were successfully prepared as thin films, and $\mathrm{Cu}-\mathrm{MOF}$ was successfully incorporated into the PS during the hydrosilylation process.

(a)
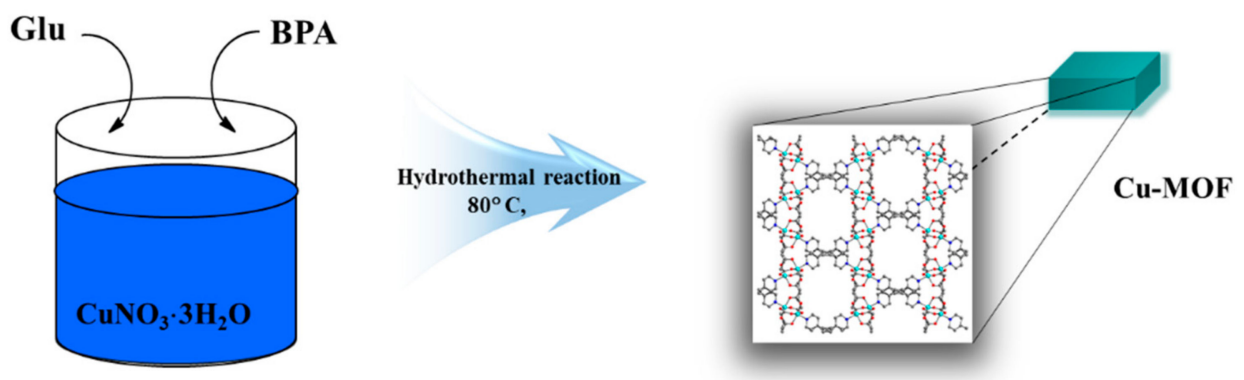

(b)
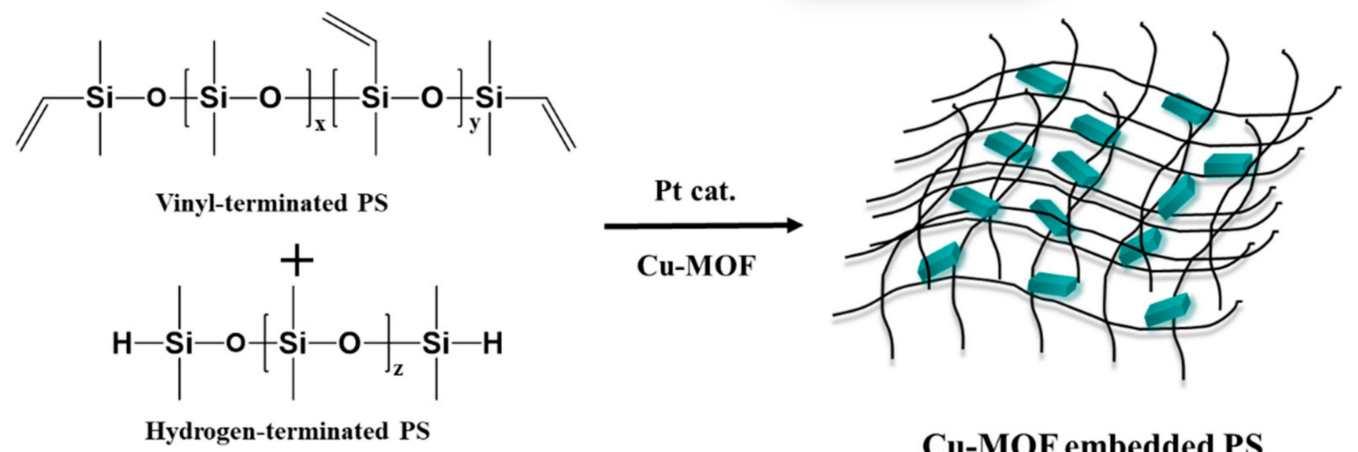

Cu-MOF embedded PS

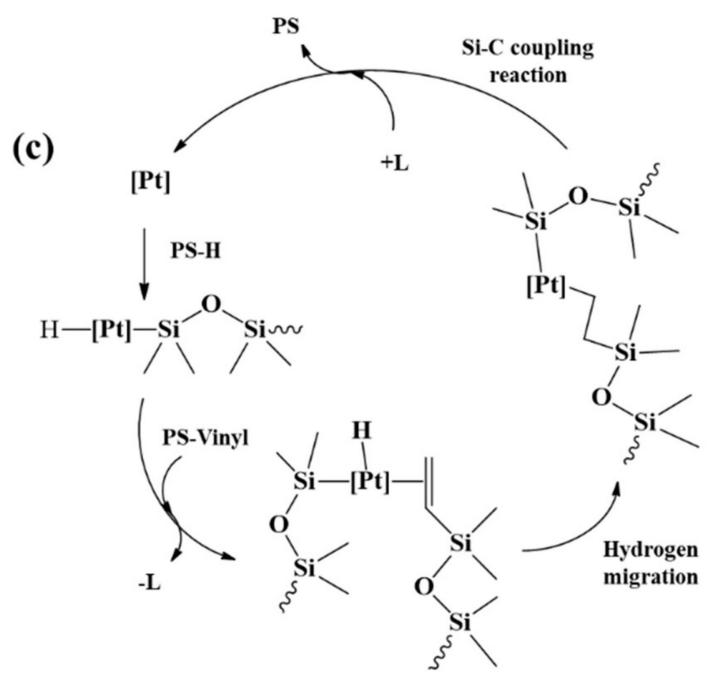

(d)

PS

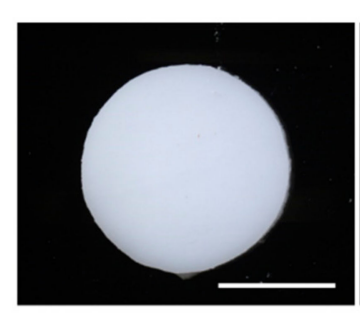

PS@Cu-MOF

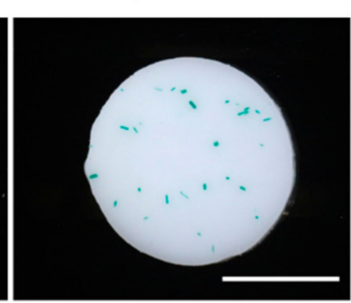

Figure 1. (a) Schematic illustration of the synthesis of Cu-MOF. (b) Hydrosilylation of vinyl-terminated PS and hydrogenterminated PS with Cu-MOF in the presence of a Pt catalyst. (c) Curing mechanism for the hydrosilylation of PS-vinyl and PS-H containing a Pt catalyst. (d) Photographic images of PS and the PS@Cu-MOF. Scale bar: $0.5 \mathrm{~cm}$.

\subsection{Characterization of the PS@Cu-MOF}

The PXRD patterns of PS, Cu-MOF, and PS@Cu-MOF were analyzed to study the nature of crystallinity of each sample. As illustrated in Figure 2a, two broad intense peaks were observed for PS and PS@Cu-MOF, namely a large peak at $\sim 12.8^{\circ}$ and a smaller and broader peak at $22.6^{\circ}$, which were assigned to $\mathrm{PS}$ and $\mathrm{TiO}_{2}$, respectively, and corresponded with the previous reported literature [52,53]. Furthermore, PS@Cu-MOF exhibited additional crystalline peaks at $2 \theta=6.8^{\circ}$, pertaining to the crystal planes of Cu-MOF (Figure S1). These results confirm the successful embedding of $\mathrm{Cu}-\mathrm{MOF}$ in the PS networks. Figure $2 \mathrm{~b}$ shows typical DSC scans performed at identical heating rates for the PS and PS@Cu-MOF 
samples. The glass transition temperatures $\left(\mathrm{T}_{\mathrm{g}}\right)$ of both samples were observed similarly below $-100{ }^{\circ} \mathrm{C}$, indicating that the $\mathrm{T}_{\mathrm{g}}$ was not affected by the embedding of $\mathrm{Cu}-\mathrm{MOF}$ on the PS. In addition, a single melting peak at around $-40{ }^{\circ} \mathrm{C}$ was observed for the two PS-based species, which is common in cross-linked PS materials owing to the inability of the crosslinks to crystallize [54]. The thermogravimetric analyses of PS and PS@Cu-MOF were also carried out, wherein a single weight loss step (43.0 and $42.3 \%$, respectively, at $511^{\circ} \mathrm{C}$ ) and similar thermal degradation paths were observed in an inert atmosphere (Figure 2c). This decomposition tendency suggests that the two PS networks are not significantly different from one another, i.e., the incorporation of $\mathrm{Cu}-\mathrm{MOF}$ does not significantly affect the PS network. FT-IR spectral analysis was also performed. Figure S4 shows four strong and sharp peaks: the asymmetric C-H bending at $2961 \mathrm{~cm}^{-1}$, the symmetric C-H bending at $1258 \mathrm{~cm}^{-1}$, the asymmetric $\mathrm{Si}-\mathrm{O}-\mathrm{Si}$ stretching at $1009 \mathrm{~cm}^{-1}$, and $\mathrm{Si}-\mathrm{C}$ stretching at $785 \mathrm{~cm}^{-1}$ in both PS@Cu-MOF and PS samples, whereas the Cu-MOF related peak did not occur from PS@Cu-MOF due to their low concentration in PS [55].

(a)

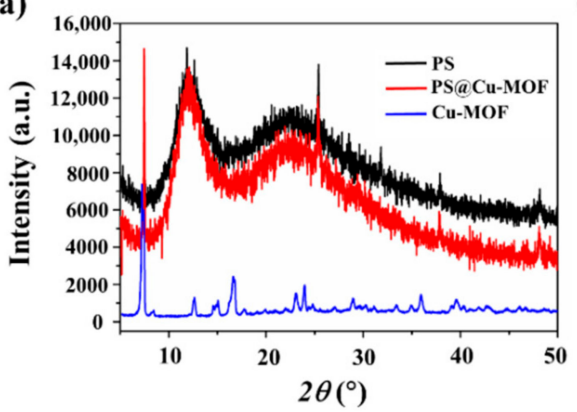

(b)

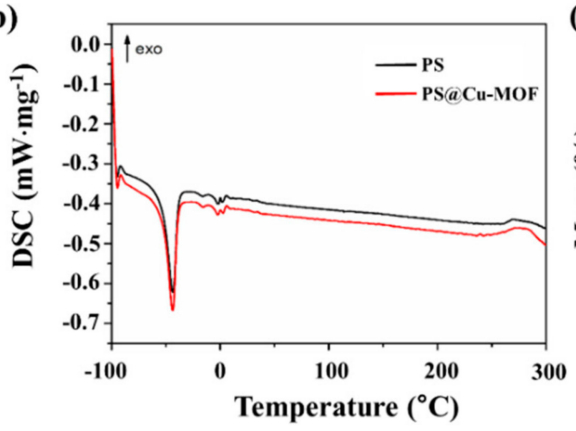

(c)

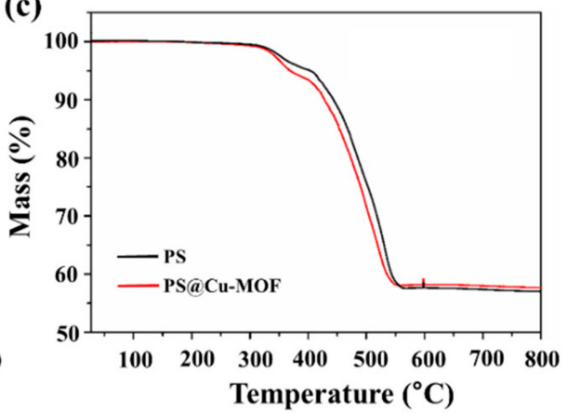

Figure 2. Characterization of PS and PS@Cu-MOF; (a) PXRD patterns, (b) DSC scans, and (c) TGA profiles.

Moreover, analysis by SEM-EDS was carried out to obtain the morphologies and chemical compositions of the control PS and the PS@Cu-MOF. Figure 3 shows representative SEM images in addition to the corresponding mapping results for both species. More specifically, $\mathrm{Si}, \mathrm{Ti}$, and $\mathrm{Pt}$ were evenly spread throughout both networks ( $\mathrm{C}$ and $\mathrm{O}$ were skipped), and the additional element of Cu was also found in the EDS spectrum of PS@CuMOF. These data confirm the embedding of $\mathrm{Cu}-\mathrm{MOF}$ on PS following the above-described hydrosilylation reaction and agree with aforementioned PXRD patterns.

\subsection{Mechanical Properties of PS@Cu-MOF}

The storage moduli of PS and PS@Cu-MOF were measured to analyze their mechanical properties. As shown in Figure 4a, PS@Cu-MOF exhibited stable rheological properties $(50.6 \pm 0.2 \mathrm{kPa})$ and a similar modulus to PS $(49.8 \pm 0.3 \mathrm{kPa})$. Figure $4 \mathrm{~b}$ shows the swelling behaviors of PS@Cu-MOF and PS, where low swelling ratios $(1.01 \pm 0.01$ and $1.03 \pm 0.03)$ are apparently due to the inherent hydrophobicity of PS. These results therefore indicate that PS@Cu-MOF has a polymeric network structure very similar to that of the control PS, and that the small amount of $\mathrm{Cu}-\mathrm{MOF}$ does not significantly affect the mechanical strength.

\subsection{Antibacterial Activity Tests}

The antibacterial activity of $\mathrm{Cu}-\mathrm{MOF}$ has been previously reported against various strains of bacteria, including Gram-negative and Gram-positive bacteria, with $\mathrm{Cu}-\mathrm{MOF}$ exhibiting excellent bactericidal properties [45]. We therefore decided to embed an antibacterial $\mathrm{Cu}-\mathrm{MOF}$ to the PS to develop a new medicinal sheet, and we tested the bactericidal effects of both PS and the prepared PS@Cu-MOF against E. coli, S. aureus, and MRSA at $100 \mu \mathrm{g} \cdot \mathrm{mL}^{-1}$ to evaluate the material potential for medicinal application. As shown in Figure 5 and Table 1, the bactericidal effect of the control PS increased in the following order: MRSA $(20.0 \%)<$ S. aureus $(31.8 \%)<$ E. coli $(44.8 \%)$; this can be attributed to the antibacterial properties of the $\mathrm{Pt}$ catalyst and the $\mathrm{TiO}_{2}$ additive [56,57]. Upon embedding 
the Cu-MOFs in PS, the bactericidal effect was significantly increased as follows: MRSA $(81.6 \%)<$ S. aureus $(87.7 \%)<$ E. coli $(88.8 \%)$. These results demonstrate that PS@Cu-MOF exhibits an excellent bactericidal effect on both Gram-negative bacteria (E. coli) and Grampositive bacteria (S. aureus, MRSA) and shows better antibacterial activity than previously reported antibacterial polysiloxanes [58]. Graphene oxide-catechol composite (GO-DMA) was modified onto the surface of PDMS. The antibacterial activity of GO-DMA-PDMS was evaluated against E. coli and S. aureus. Antibacterial GO-DMA-PDMS killed S. aureus (42\%) and E. coli (37\%). Based on this result, Cu-MOF embedded PS is more bioactive than the previously published antibacterial surface-coated PDMS.

PS
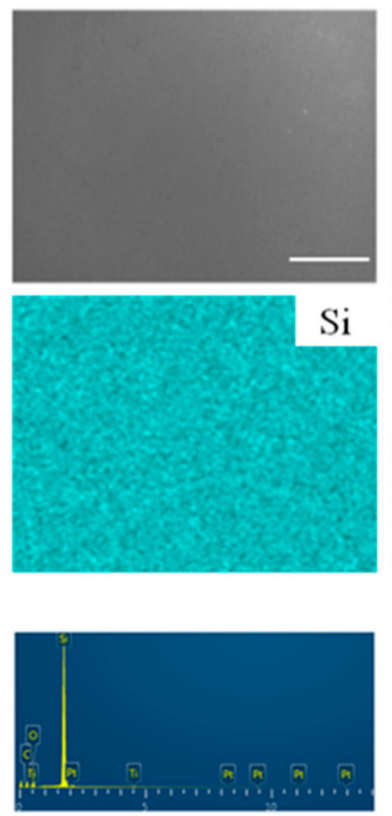
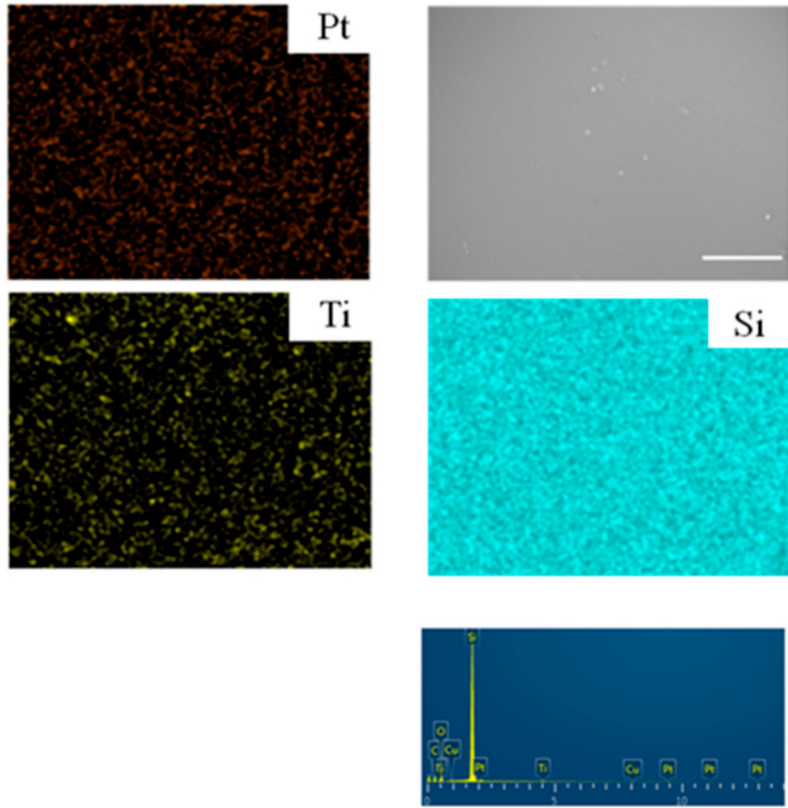

\section{PS $a$ Cu-MOF}
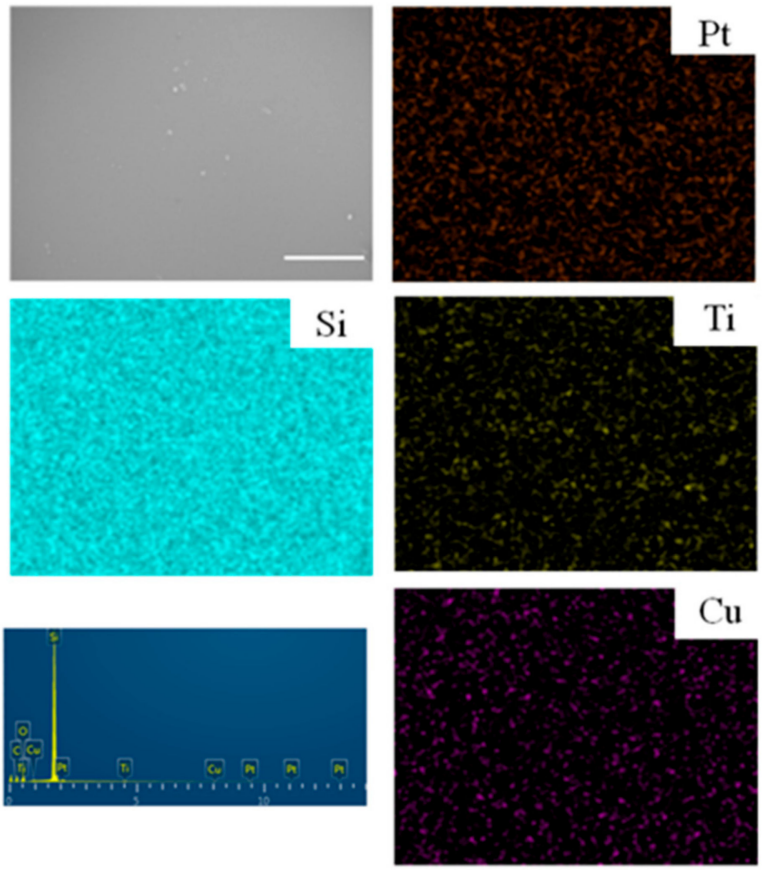

Figure 3. SEM images of PS and PS@Cu-MOF with the accompanying EDS spectra and corresponding elemental maps. Scale bar: $50 \mu \mathrm{m}$.

(a)

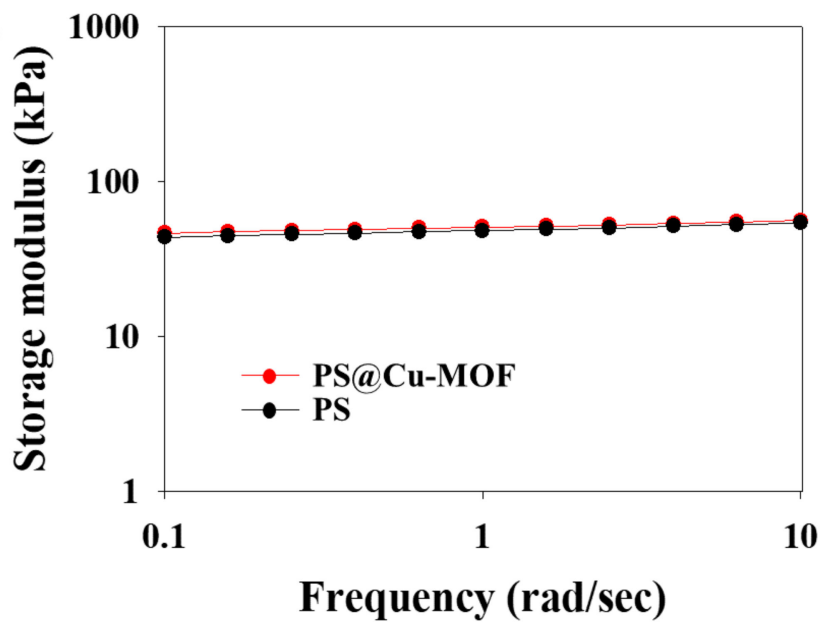

(b)

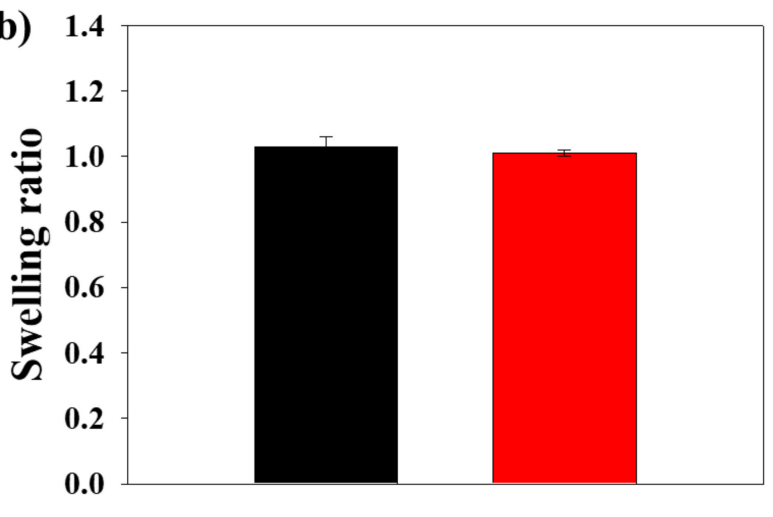

PS

PS@Cu-MOF

Figure 4. Physical properties of PS and PS@Cu-MOF. (a) Storage modulus and (b) swelling ratio of PS and PS@Cu-MOF $(n=4)$. 

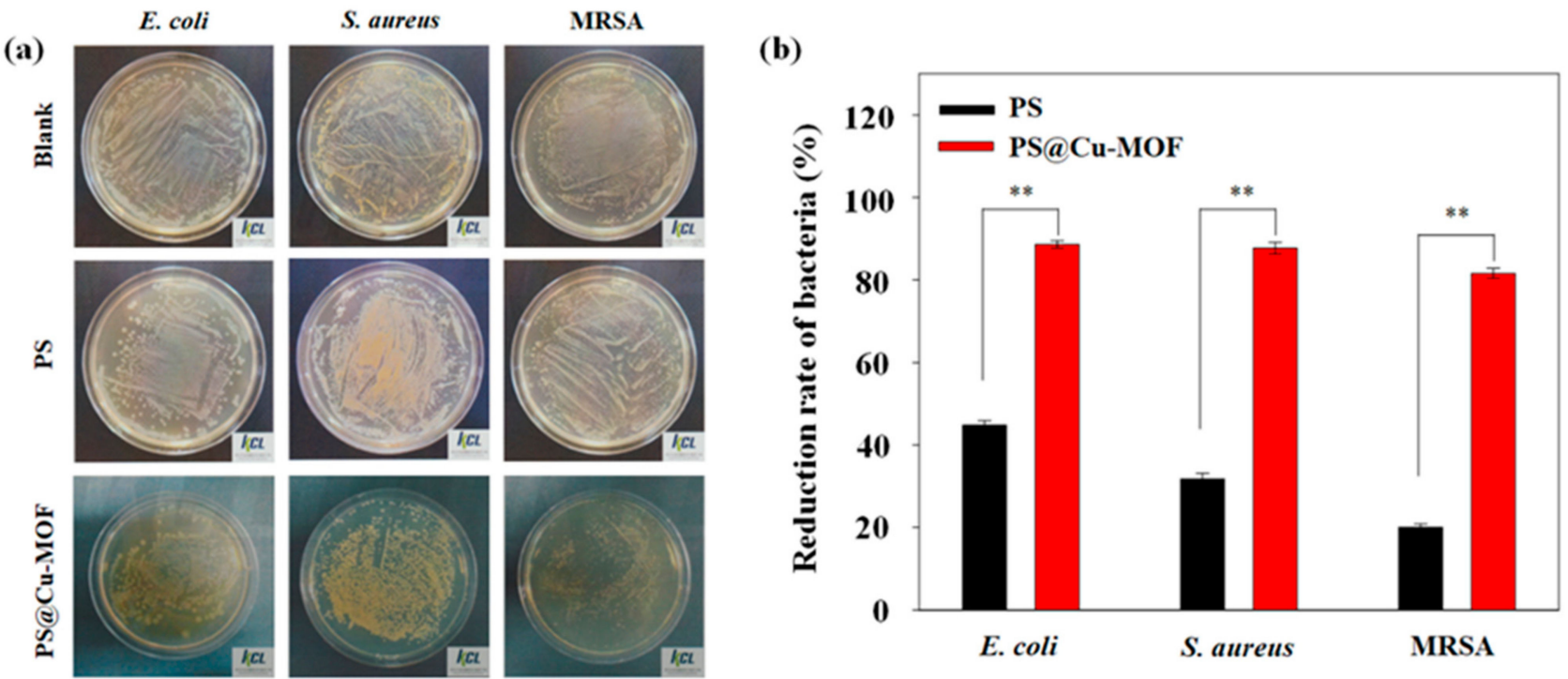

Figure 5. (a) Representative images of bacteria grown on PS and PS@Cu-MOF after incubation for 24 h: Top (blank), middle (PS), and bottom (PS@Cu-MOF); left to right: E. coli, S. aureus, and MRSA. (b) The antibacterial efficiency of PS and PS@Cu-MOF towards E. coli, S. aureus, and MRSA (means \pm standard deviation with $\mathrm{n}=3$; **: $p<0.01$ ).

Table 1. Antibacterial activity of the MOF-embedded PS against various bacteria.

\begin{tabular}{|c|c|c|c|c|}
\hline \multicolumn{2}{|c|}{ Test Items } & \multicolumn{3}{|c|}{ Test Results ${ }^{a, b}$} \\
\hline & & $\begin{array}{l}\text { Early Conc. } \\
\left(\mathrm{cfu} \cdot \mathrm{mL}^{-1}\right)\end{array}$ & $\begin{array}{l}\text { After } 24 \mathrm{~h} \text {, Conc. } \\
\quad\left(\mathrm{cfu} \cdot \mathrm{mL}^{-1}\right)\end{array}$ & $\begin{array}{c}\text { Reduction Rate of } \\
\text { Bacteria (\%) }\end{array}$ \\
\hline \multirow{4}{*}{ E. coli } & blank & $3.4 \times 10^{5}$ & $9.8 \times 10^{6}$ & - \\
\hline & PS & $3.4 \times 10^{5}$ & $5.4 \times 10^{6}$ & 44.8 \\
\hline & blank & $1.2 \times 10^{5}$ & $3.8 \times 10^{6}$ & - \\
\hline & PS@Cu-MOF & $1.2 \times 10^{5}$ & $4.3 \times 10^{5}$ & 88.6 \\
\hline \multirow{4}{*}{ S. aureus } & blank & $3.6 \times 10^{5}$ & $9.1 \times 10^{6}$ & - \\
\hline & PS & $3.6 \times 10^{5}$ & $6.2 \times 10^{6}$ & 31.8 \\
\hline & blank & $1.6 \times 10^{5}$ & $2.2 \times 10^{6}$ & - \\
\hline & PS@Cu-MOF & $1.6 \times 10^{5}$ & $2.7 \times 10^{5}$ & 87.7 \\
\hline \multirow{4}{*}{ MRSA } & blank & $3.6 \times 10^{5}$ & $9.0 \times 10^{6}$ & - \\
\hline & PS & $3.6 \times 10^{5}$ & $7.2 \times 10^{6}$ & 20.0 \\
\hline & blank & $3.0 \times 10^{5}$ & $9.8 \times 10^{5}$ & - \\
\hline & PS@Cu-MOF & $3.0 \times 10^{5}$ & $1.8 \times 10^{5}$ & 81.6 \\
\hline
\end{tabular}

a test method: KCL-FIR1003: 2018. ${ }^{\mathrm{b}}$ test environment: $(37.0 \pm 0.2)^{\circ} \mathrm{C}$, Conc. $100 \mu \mathrm{g} \cdot \mathrm{mL}^{-1}$.

\subsection{Ion Release Tests}

Degradation tests were then performed on the PS@Cu-MOF in $0.9 \%$ PBS at $25{ }^{\circ} \mathrm{C}$ for $6,12,24$, and $48 \mathrm{~h}$, and the quantity of copper metal ions released from $\mathrm{Cu}-\mathrm{MOF}$ was measured by ICP-MS. As shown in Figure 6, the concentration of metal ions released from PS@Cu-MOF increased to $0.112 \mu \mathrm{g} \cdot \mathrm{mL}^{-1}$ during the initial $6 \mathrm{~h}$, and then decreased until the $24 \mathrm{~h}$ point $\left(0.065 \mu \mathrm{g} \cdot \mathrm{mL}^{-1}\right)$, after which it slightly increased again up to $48 \mathrm{~h}$ $\left(0.067 \mu \mathrm{g} \cdot \mathrm{mL}^{-1}\right)$. The average concentration of $\mathrm{Cu}(\mathrm{II})$ ions released from PS@Cu-MOF after $24 \mathrm{~h}$, i.e., $0.089 \mu \mathrm{g} \cdot \mathrm{mL}^{-1}$, was lower than in the case of the $\mathrm{Cu}-\mathrm{MOF}$ alone $[37,38]$. These results indicate that PS@Cu-MOF maintains its robust framework on the polymer network while also exhibiting excellent bactericidal properties against the various bacterial strains without the participation of released metal ions. 


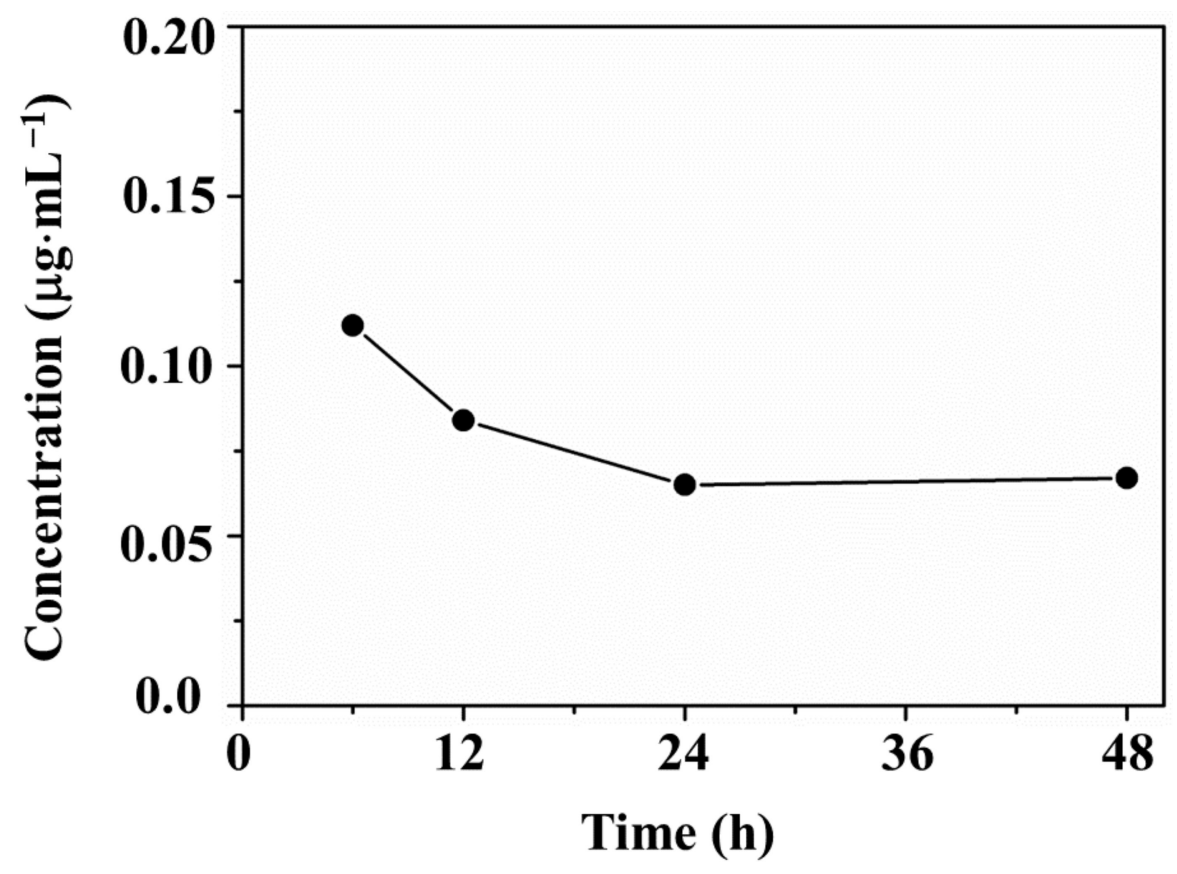

Figure 6. Concentration of $\mathrm{Cu}(\mathrm{II})$ ions released from PS@Cu-MOF $(1 \mathrm{mg})$ in $0.9 \%$ PBS $(1 \mathrm{~mL})$.

\subsection{Cytotoxicity of PS@Cu-MOF}

Finally, we studied the cell biocompatibility of PS@Cu-MOF based on a direct contact method [47]. To verify the toxicity of the PS itself, PS (i.e., without the Cu-MOF) was prepared using the same method employed for its use as a positive control. Furthermore, as an additional positive control (blank), a mouse embryonic fibroblast (MEF) monolayer without any PS or PS@MOF contact was prepared. As a negative control, an MEF monolayer contact with a $10 \% \mathrm{EtOH}$ solution was used. The viability of the MEF monolayer was monitored using live/dead staining as well as an MTS assay. As shown in the fluorescence microscopy images (Figure 7a), the cell viabilities for the blank, PS, and PS@Cu-MOF (100 $\mu \mathrm{g} \cdot \mathrm{mL}^{-1}$ ) samples exceeded $98 \%$ for $1 \mathrm{~d}$ after culture, whereas in the case of the MEF monolayer, the majority of cells died upon exposure to EtOH. It was found that the cells gradually adhered, spread, and flattened on the surface after seeding, prior to forming a confluent-like layer that survived for $3 \mathrm{~d}$; this was not observed in the case of the EtOH group. These results indicate that neither the MOF-embedded PS nor the PS alone were toxic to the cells. Further quantification was carried out using an MTS assay (Figure 7b), wherein extracted cell culture medium solutions from PS and PS@Cu-MOF were serially diluted. For example, $100 \%$ refers to the original extraction medium, and $25 \%$ indicates a four times dilution from the original extraction medium. Following formation of the MEF monolayer, the culture medium was changed to the desired concentration medium containing the extract solution, and cultured. The obtained MTS results demonstrated the good cytocompatibilities of PS and PS@Cu-MOF, as the MEF viability was >93\% in all cases, whereas the majority of MEFs died upon exposure to $\mathrm{EtOH}$, thereby confirming the low cytotoxicity of the PS and PS@Cu-MOF extracts. 
(a)

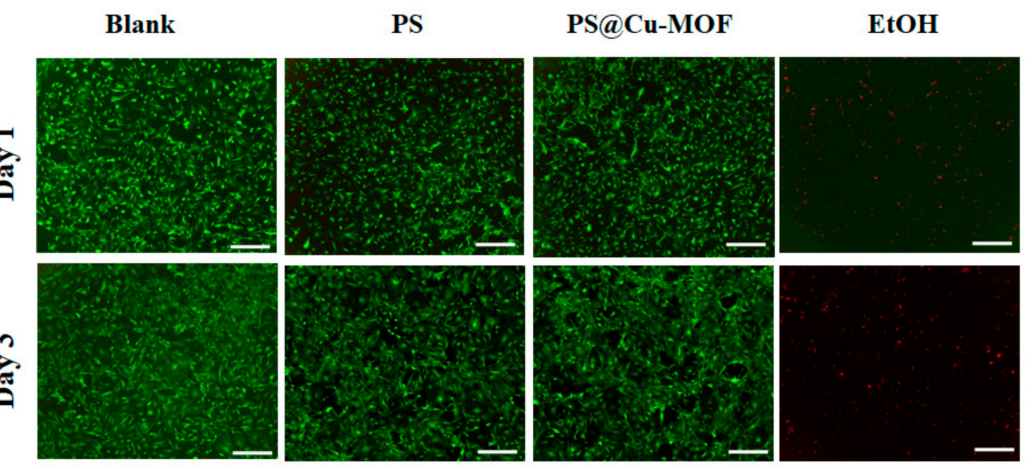

(b)

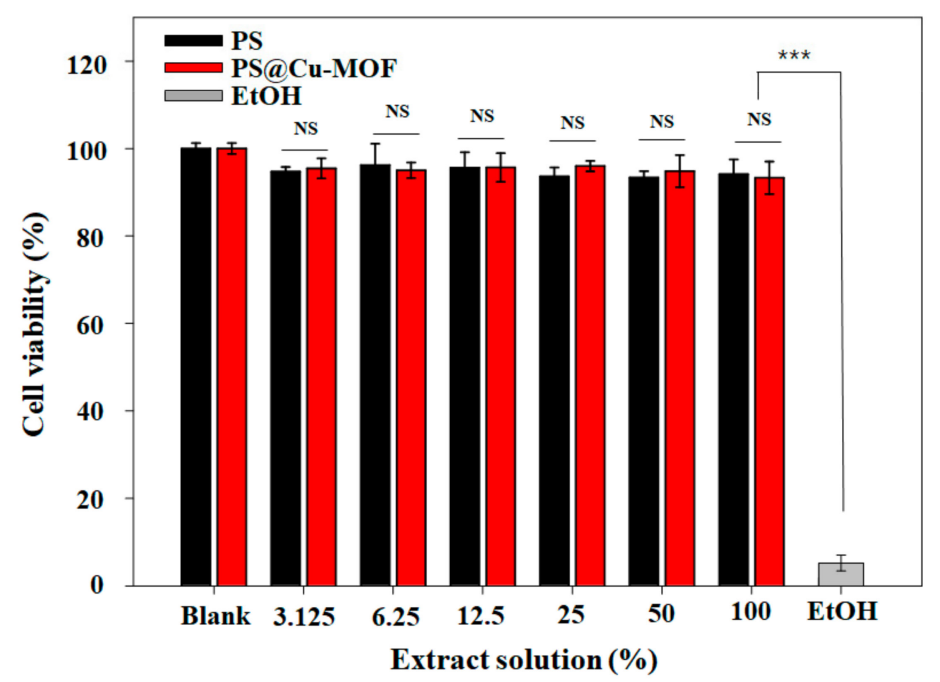

Figure 7. (a) Staining images of the live/dead MEFs after contact with PS only or PS@Cu-MOF for 1 or $3 \mathrm{~d}$. Cells cultured without any PS contact were used as a positive control. As a negative control, cells exposed to EtOH were used. (b) In vitro cytotoxicity of the extract solution of PS and PS@CuMOF to MEFs $(n=4) ;$ means \pm standard deviation with $n=4$; NS: not significant; ${ }^{* * *} p<0.001$. Scale bar: $200 \mu \mathrm{m}$.

\section{Conclusions}

In this work, we successfully modified the surfaces of polysiloxanes (PSs) with coppercontaining metal-organic frameworks (Cu-MOFs) via a hydrosilylation reaction. Modification was performed at room temperature without the requirement for any special equipment. The bactericidal activities of the Cu-MOF-embedded PS (i.e., PS@Cu-MOF) and the control PS were tested against three strains of bacteria, namely E. coli, S. aureus, and MRSA. Importantly, PS@Cu-MOF exhibited superior antibacterial properties toward the tested bacteria than the control PS, in addition to a low cytotoxicity toward mouse embryonic fibroblasts at a concentration of $100 \mu \mathrm{g} \cdot \mathrm{mL}^{-1}$. In addition, $\mathrm{Cu}$ (II) ion release tests confirmed the excellent stability of PS@Cu-MOF in phosphate-buffered saline. Furthermore, the physical and thermal properties of PS@Cu-MOF, such as its phase transition, swelling ratio, and thermogravimetric profile, were comparable to those of the control PS. Moreover, its low cytotoxicity and high bactericidal activity indicate the potential of PS@CuMOF as a promising new candidate for medicinal applications, such as in implants, the treatment of skin disease, wound healing, and drug delivery. In summary, we attempted to efficiently improve the antibacterial activity of PS@Cu-MOF utilizing the synergy effect by blending with other additives, and we drove the development of another new bioactive PS. We believe that our findings could be useful for manufacturing a silicone-based implanting device with antibacterial activity in a straightforward and economically competitive way. However, further work, including in vivo experiments, is required to promote the future use of $\mathrm{Cu}-\mathrm{MOF}$-embedded PS as a new generation of powerful antibacterial agents and devices with wide-ranging applications. 
Supplementary Materials: The following are available online at https: / /www.mdpi.com/2079-4 991/11/3/719/s1, Figure S1: PXRD pattern of Cu-MOF, Figure S2: FT-IR spectrum of Cu-MOF, Figure S3: Crystal structure of Cu-MOF, Figure S4: FT-IR spectrum of PS and PS@Cu-MOF.

Author Contributions: Conceptualization, K.G. and D.N.L.; methodology, K.G., Y.K., H.C., S.-H.Y. and S.-J.K.; validation, H.C.; formal analysis, K.G., Y.K., S.L.; Investigation, S.-H.Y.; data curation, K.G., Y.K., H.C., S.L., S.-H.Y. and S.-J.K.; writing-original draft preparation, K.G.; writing-review and editing, Y.K., S.L. and D.N.L.; supervision, D.N.L.; funding acquisition, K.G., Y.K., S.L. and D.N.L. All authors have read and agreed to the published version of the manuscript.

Funding: This work was supported by the Basic Science Research Program of the National Research Foundation of Korea (2017R1A6A3A11030955, 2018R1D1A1B07045327, and 2021R1A2C1004285) and by Kwangwoon University in the year 2020. This work was also supported by the Center for Women in Science, an Engineering and Technology (WISET) Grant funded by the Ministry of Science and ICT (MSIT) under the Program for Returners into R\&D.

Institutional Review Board Statement: Not applicable.

Informed Consent Statement: Informed consent was obtained from all subjects involved in the study.

Data Availability Statement: Data is available on the request from the corresponding author.

Acknowledgments: The authors would also like to thank the Korean Basic Science Institute in Seoul for carrying out the ICP-MS analysis.

Conflicts of Interest: The authors declare no conflict of interest.

\section{References}

1. Chen, C.Z.S.; Cooper, S.L. Recent advances in antimicrobial dendrimers. Adv. Mater. 2000, 12, 843-846. [CrossRef]

2. Gabriel, G.J.; Som, A.; Madkour, A.E.; Eren, T.; Tew, G.N. Infectious disease: Connecting innate immunity to biocidal polymers. Mater. Sci. Eng. R. Rep. 2007, 57, 28-64. [CrossRef] [PubMed]

3. Hadjesfandiari, N.; Yu, K.; Mei, Y.; Kizhakkedathu, J.N. Polymer brush-based approaches for the development of infectionresistant surfaces. J. Mater. Chem. B 2014, 2, 4946-4978. [CrossRef]

4. Zhao, D.; Zhu, T.; Li, J.; Cui, L.; Zhang, Z.; Zhuang, X.; Ding, J. Poly(lactic-co-glycolic acid)-based composite bone-substitute materials. Bioact. Mater. 2021, 6, 346-360. [CrossRef]

5. Zhu, T.; Cui, Y.; Zhang, M.; Zhao, D.; Liu, G.; Ding, J. Engineered three-dimensional scaffolds for enhanced bone regeneration in osteonecrosis. Bioact. Mater. 2020, 5, 584-601. [CrossRef]

6. Li, S.; Dong, S.; Xu, W.; Tu, S.; Yan, L.; Zhao, C.; Ding, J.; Chen, X. Antibacterial hydrogels. Adv. Sci. 2018, 5, 1700527. [CrossRef] [PubMed]

7. Timofeeva, L.; Kleshcheva, K. Antimicrobial polymers: Mechanism of action, factors of activity, and applications. Appl. Microbiol. Biotechnol. 2011, 89, 475-492. [CrossRef] [PubMed]

8. Rupa, S.; Dutta, B.; Singh, S.P.; Rathor, A. Research article case report: Silicone implant in augmentation of saddle nose. Int. J. Recent Sci. Res. 2013, 4, 1661-1662.

9. Elist, J.J.; Shirvanian, V.; Lemperle, G. Surgical treatment of penile deformity due to curvature using a subcutaneous soft silicone implant: Case report. Open J. Urol. 2014, 4, 91-97. [CrossRef]

10. Beigbeder, A.; Labruyère, C.; Viville, P.; Pettitt, M.E.; Callow, M.E.; Callow, J.A. Surface and fouling-release properties of silicone/organomodified montmorillonite coatings. J. Adhes. Sci. Tech. 2011, 25, 1689-1700. [CrossRef]

11. Mark, J.E. Some interesting things about polysiloxanes. Acc. Chem. Res. 2004, 37, 946-953. [CrossRef]

12. Hogg, A.; Aellen, T.; Uhl, S.; Graf, B.; Keppner, H.; Tardy, Y.; Burger, J. Ultra-thin layer packaging for implantable electronic devices. J. Micromech. Microeng. 2013, 23, 075001. [CrossRef]

13. Teo, A.J.T.; Mishra, A.; Park, I.; Kim, Y.-J.; Park, W.-T.; Yoon, Y.-J. Polymeric biomaterials for medical implants and devices. ACS Biomater. Sci. Eng. 2016, 2, 454-472. [CrossRef]

14. Hassler, C.; von Metzen, R.P.; Ruther, P.; Stieglitz, T. Characterization of parylene $\mathrm{C}$ as an encapsulation material for implanted neural prostheses. J. Biomed. Mater. Res. Part B Appl. Biomater. 2010, 93, 266-274. [CrossRef]

15. Van Zele, D.; Heymans, O. Breast implants. A review. Acta Chir. Belg. 2004, 104, 158-164. [CrossRef]

16. Lo, R.; Li, P.Y.; Saati, S.; Agrawal, R.; Humayun, M.S.; Meng, E. A refillable microfabricated drug delivery device for treatment of ocular diseases. Lab Chip 2008, 8, 1027-1030. [CrossRef]

17. Lo, R.; Li, P.Y.; Saati, S.; Agrawal, R.N.; Humayun, M.S.; Meng, E. A passive MEMS drug delivery pump for treatment of ocular diseases. Biomed. Microdevices 2009, 11, 959-970. [CrossRef]

18. Yilgör, E.; Yilgör, I. Silicone containing copolymers: Synthesis, properties and applications. Prog. Polym. Sci. 2014, 39, 1165-1195. [CrossRef] 
19. Rahimi, A.; Mashak, A. Review on rubbers in medicine: Natural, silicone and polyurethane rubbers. Plast. Rubber Compos. 2013, 42, 223-230. [CrossRef]

20. Nikolova, M.P.; Chavali, M.S. Recent advances in biomaterials for 3D scaffolds: A review. Bioact. Mater. 2019, 4, 271-292. [CrossRef] [PubMed]

21. Qin, Y.; Howlader, M.M.R.; Deen, M.J.; Haddara, Y.M.; Selvaganapathy, P.R. Polymer integration for packaging of implantable sensors. Sens. Actuat. B Chem. 2014, 202, 758-778. [CrossRef]

22. Kugel, A.; Chisholm, B.; Ebert, S.; Jepperson, M.; Jarabek, L.; Stafslien, S. Antimicrobial polysiloxane polymers and coatings containing pendant. Polym. Chem. 2010, 1, 442-452. [CrossRef]

23. Islas, M.S.; Medina, J.J.M.; López Tévez, L.L.; Rojo, T.; Lezama, L.; Merino, M.G.; Calleros, L.; Cortes, M.A.; Puyol, R.M.; Echeverría, G.A.; et al. Antitumoral, antihypertensive, antimicrobial, and antioxidant effects of an octanuclear copper (II)-telmisartan complex with an hydrophobic nanometer hole. Inorg. Chem. 2014, 53, 5724-5737. [CrossRef] [PubMed]

24. Jaros, S.W.; Guedes da Silva, M.F.C.; Król, J.; Oliveira, M.C.; Smoleński, P.; Pombeiro, A.J.L.; Kirillov, A.M. Bioactive silver-organic networks assembled from 1,3,5-triaza-7-phosphaadamantane and flexible cyclohexanecarboxylate blocks. Inorg. Chem. 2016, 55, 1486-1496. [CrossRef]

25. Wang, L.; Yang, W.; Zhu, W.; Guan, X.; Xie, Z.; Sun, Z.-M. A nanosized $\{$ Ag@Ag12\} "molecular windmill" templated by polyoxometalates anions. Inorg. Chem. 2014, 53, 11584-11588. [CrossRef] [PubMed]

26. Chojnowski, J.; Fortuniak, W.; Rościszewski, P.; Werel, W.; Łukasiak, J.; Kamysz, W.; Hałasa, R. Polysilsesquioxanes and oligosilsesquioxanes substituted by alkylammonium salts as antibacterial biocides. J. Inorg. Organomet. Polym. Mater. 2006, 16, 219-230. [CrossRef]

27. Mansouri, J.; Truong, V.K.; MacLaughlin, S.; Mainwaring, D.E.; Moad, G.; Dagley, I.J.; Ivanova, E.P.; Crawford, R.J.; Chen, V. Polymerization-Induced Phase Segregation and Self-Assembly of Siloxane Additives to Provide Thermoset Coatings with a Defined Surface Topology and Biocidal and Self-Cleaning Properties. Nanomaterials 2019, 9, 1610. [CrossRef] [PubMed]

28. Mizerska, U.; Fortuniak, W.; Chojnowski, J.; Halasa, R.; Konopacka, A.; Werel, W. Polysiloxane cationic biocides with imidazolium salt (ImS) groups, synthesis and antibacterial properties. Eur. Polym. J. 2009, 45, 779-787. [CrossRef]

29. Mizerska, U.; Fortuniak, W.; Chojnowski, J.; Turecka, K.; Konopacka, A.; Werel, W. Antimicrobial siloxane statistical and graft copolymers substituted with t-butylamine and t-butylammonium biocidal functions. J. Inorg. Organomet. Polym. Mater. 2010, 20, 554-563. [CrossRef]

30. Rozga-Wijas, K.; Mizerska, U.; Fortuniak, W.; Chojnowski, J.; Halasa, R.; Werel, W. Quaternary ammonium salts (QAS) modified polysiloxane biocide supported on silica materials. J. Inorg. Organomet. Polym. Mater. 2007, 17, 605-613. [CrossRef]

31. Chisholm, B.J.; Majumdar, P. Antimicrobial Polysiloxane Materials Containing Metal Species. U.S. Patent 8,709,394 B2, 29 April 2014.

32. Yilgor, E.; Nugay, I.I.; Bakan, M.; Yilgor, I. Antibacterial silicone-urea/organoclay nanocomposites. Silicon 2009, 1, 183-190. [CrossRef]

33. Prasse, M.; Christofferson, A.J.; Elbourne, A.; Cheeseman, S.; Shi, Y.; Rolland, M.; Cozzolino, D.; Chapman, J.; McConville, C.F.; Crawford, R.J.; et al. Conformationally tuned antibacterial oligomers target the peptidoglycan of Gram-positive bacteria. J. Colloid Interface Sci. 2020, 580, 850-862.

34. Liu, Q.; Ning, D.; Li, W.-J.; Du, X.-M.; Wang, Q.; Li, Y.; Ruan, W.-J. A point-of-care diagnostics logic detector based on glucose oxidase immobilized lanthanide functionalized metal-Organic frameworks. Analyst 2019, 114, 1916-1922. [CrossRef]

35. Sava Gallis, D.F.; Butler, K.S.; Agola, J.O.; Pearce, C.J.; McBride, A.A. Antibacterial countermeasures via metal-organic frameworksupported sustained therapeutic release. ACS Appl. Mater. Interfaces 2019, 11, 7782-7791. [CrossRef] [PubMed]

36. Lu, X.; Ye, J.; Zhang, D.; Xie, R.; Bogale, R.F.; Sun, Y.; Zhao, L.; Zhao, Q.; Ning, G. Silver carboxylate metal-organic frameworks with highly antibacterial activity and biocompatibility. J. Inorg. Biochem. 2014, 138, 114-121. [CrossRef]

37. Wang, S.; Yan, F.; Ren, P.; Li, Y.; Wu, Q.; Fang, X.; Chen, F.; Wang, C. Incorporation of metal-organic frameworks into electrospun chitosan/poly (vinyl alcohol) nanofibrous membrane with enhanced antibacterial activity for wound dressing application. Int. J. Biol. Macromol. 2020, 158, 9-17. [CrossRef]

38. Rubin, H.N.; Neufeld, B.H.; Reynolds, M.M. Surface-anchored metal—Organic framework—Cotton material for tunable antibacterial copper delivery. ACS Appl. Mater. Interfaces 2018, 10, 15189-15199. [CrossRef]

39. Sharma, V.K.; Yngard, R.A.; Lin, Y. Silver nanoparticles: Green synthesis and their antimicrobial activities. Adv. Colloid Interface Sci. 2009, 145, 83-96. [CrossRef]

40. Li, H.; Duan, X.; Liu, G.; Liu, X. Photochemical synthesis and characterization of Ag/ $\mathrm{TiO}_{2}$ nanotube composites. J. Mater. Sci. 2008, 43, 1669-1676. [CrossRef]

41. Zeng, H.; Zhao, C.; Qiu, J.; Yang, Y.; Chen, G. Preparation and optical properties of silver nanoparticles induced by a femtosecond laser irradiation. J. Cryst. Growth 2007, 300, 519-522. [CrossRef]

42. Chen, Y.; Han, Q.; Wang, Y.; Zhang, Q.; Qiao, X. Synthesis of pyridinium polysiloxane for antibacterial coating in supercritical carbon dioxide. J. Appl. Polym. Sci. 2015, 132, 41723. [CrossRef]

43. Jońca, J.; Tukaj, C.; Werel, W.; Mizerska, U.; Fortuniak, W.; Chojnowski, J. Bacterial membranes are the target for antimicrobial polysiloxane-methacrylate copolymer. J. Mater. Sci. Mater. Med. 2016, 27, 55. [CrossRef] [PubMed]

44. Gwon, K.; Han, I.; Lee, S.; Kim, Y.; Lee, D.N. Novel metal—Organic framework-based photocrosslinked hydrogel system for efficient antibacterial applications. ACS Appl. Mater. Interface 2020, 12, 20234-20242. [CrossRef] 
45. Jo, J.H.; Kim, H.-C.; Huh, S.; Kim, Y.; Lee, D.N. Antibacterial activities of Cu-MOFs containing glutarates and bipyridyl ligands. Dalton Trans. 2019, 48, 8084-8093. [CrossRef]

46. Hwang, I.H.; Bae, J.M.; Kim, W.-S.; Jo, Y.D.; Kim, C.; Kim, Y.; Kim, S.-J.; Huh, S. Bifunctional 3D Cu-MOFs containing glutarates and bipyridylligands: Selective CO2sorption and heterogeneous catalysis. Dalton Trans. 2012, 41, 12759. [CrossRef]

47. Gwon, K.; Jo, E.-J.; Sahu, A.; Lee, J.Y.; Kim, M.-G.; Tae, G. Improved near infrared-mediated hydrogel formation using diacrylated Pluronic F127-coated upconversion nanoparticles. Mater. Sci. Eng. C 2018, 90, 77-84. [CrossRef]

48. Cheng, X.; Liu, J.; Wang, L.; Wang, R.; Liu, Z.; Zhou, R. An enzyme-mediated in situ hydrogel based on polyaspartamide derivatives for localized drug delivery and 3D scaffolds. RSC Adv. 2016, 6, 101334-101346. [CrossRef]

49. Siew, W.Y.; Abu Bakar, N.H.H.; Abu Bakar, M. The influence of green synthesis on the formation of various copper benzene-1,3,5tricarboxylate compounds. Inorg. Chim. Acta 2018, 482, 53-61. [CrossRef]

50. Meister, T.K.; Riener, K.; Gigler, P.; Stohrer, J.; Herrmann, W.A.; Kühn, F.E. Platinum catalysis revisited-Unraveling principles of catalytic olefin hydrosilylation. ACS Catal. 2016, 6, 1274-1284. [CrossRef]

51. Nakajima, Y.; Shimada, S. Hydrosilylation reaction of olefins: Recent advances and perspectives. RSC Adv. 2015, 5, 20603-20616. [CrossRef]

52. Ferreira, P.; Carvalho, Á.; Ruivo Correia, T.; Paiva Antunes, B.; Joaquim Correia, I.; Alves, P. Functionalization of polydimethylsiloxane membranes to be used in the production of voice prostheses. Sci. Technol. Adv. Mater. 2013, 14, 055006. [CrossRef] [PubMed]

53. Al-Taweel, S.S.; Saud, H.R. New route for synthesis of pure anatase $\mathrm{TiO}_{2}$ nanoparticles via utrasoundassisted sol-gel method. J. Chem. Pharm. Res. 2016, 8, 620-626.

54. Fan, J.; Huang, J.; Yan, M.; Gong, Z.; Gao, L.; Chen, Y. Thermoplastic multifunctional polysiloxane-based materials from broad gradient-transition multiphase separation. J. Mater. Chem. A 2020, 8, 16376-16384. [CrossRef]

55. González-Rivera, J.; Iglio, R.; Barillaro, G.; Duce, C.; Tinè, M.R. Structural and Thermoanalytical Characterization of 3D Porous PDMS Foam Materials: The Effect of Impurities Derived from a Sugar Templating Process. Polymers 2018, 10, 616. [CrossRef] [PubMed]

56. Staszek, M.; Siegel, J.; Kolářová, K.; Rimpelová, S.; Švorčík, V. Formation and antibacterial action of Pt and Pd nanoparticles sputtered into liquid. Micro Nano Lett. 2014, 9, 778-781. [CrossRef]

57. Wanag, A.; Rokicka, P.; Kusiak-Nejman, E.; Kapica-Kozar, J.; Wrobel, R.J.; Markowska-Szczupak, A.; Morawski, A.W. Antibacterial properties of $\mathrm{TiO}_{2}$ modified with reduced graphene oxide. Ecotoxicol. Environ. Saf. 2018, 147, 788-793. [CrossRef]

58. Tu, Q.; Zhang, Q.; Wang, Y.; Jiao, J.; Peng, T.; Wang, J. Antibacterial properties of poly(dimethylsiloxane) surfaces modified with graphene oxide-catechol composite. Prog. Org. Coat. 2019, 127, 247-253. [CrossRef] 